\title{
Implementasi Etika Bisnis Islam Terhadap Pembatalan Sepihak Aplikasi Gojek Menu Go Food
}

\section{Implementation Of Islamic Business Ethics Application Unilateral Cancellation Gojek Menu Go Food}

\author{
Novia Silviani \\ Universitas Hasyim Asy'ary Tebuireng Jombang \\ noviasilviani17@gmail.com
}

\begin{abstract}
The purpose of the researcher is to find out the unilateral cancellation made by consumers when ordering food or drinks on the menu Go Food the application Gojek. Researchers use qualitative research based on empirical field and juridical data, the research method is social legal research. This research concludes that the practice of unilateral cancellation carried out by consumers has various reasons and factors that support the occurrence of unilateral cancellations and cause losses to Gojek drivers, unilateral cancellations are not only carried out by consumers but also by Gojek drivers because the application Gojek is experiencing an error. also inflicts harm on himself. The practice of cancellation by consumers on the menu Go Food is an act of breaking promises because consumers do not keep their promises to pay for their orders so that there is no loss between consumers and Gojek drivers. There is no sense of responsibility given by consumers to Gojek drivers so that one-sided cancellations will repeat itself, consumers should have a good attitude when purchasing so that Gojek drivers get wages from consumers. Islamic business ethics sees the practice of one-sided cancellation from consumers is not justified, because in Islamic business it cannot be mutually beneficial and should be mutually beneficial. The attitude of consumers who make this unilateral cancellation is not encouraged by Islamic business ethics.
\end{abstract}

Keywords: Islamic Business Ethics, Unilateral Cancellation, Go Food. 


\title{
Novia Silviani | Implementasi Etika Bisnis...
}

\begin{abstract}
Abstrak
Tujuan pada peneliti adalah untuk mengetahui pembatalan sepihak yang dilakukan oleh konsumen pada saat memesan makanan atau minuman di menu Go Food aplikasi Gojek. Peneliti menggunakan jenis penelitian kualitatif berdasarkan data lapangan dan yuridis empiris, metode penelitian adalah sosial legal research. Penelitian ini memberikan kesimpulan bahwa praktek pembatalan sepihak yang dilakukan oleh konsumen berbagai macam alasan dan faktor yang mendukung terjadinya pembatalan sepihak serta menimbulkan kerugian yang didapatkan oleh driver Gojek, pembatalan sepihak bukan hanya konsumen akan tetapi juga dilakukan oleh driver Gojek karena aplikasi Gojek sedang mengalami ke error-an juga menimbulkan kerugian pada dirinya sendiri. Praktek pembatalan oleh konsumen pada menu Go Food merupakan tindakan ingkar janji karena konsumen tidak menepati janjinya untuk membayar pesanannya sehingga tidak ada kerugian di antara konsumen maupun driver Gojek. Tidak adanya rasa tanggung jawab yang diberikan oleh konsumen ke driver Gojek sehingga akan terulang kembali pembatalan sepihak, seharusnya konsumen memiliki sikap yang baik saat pembelian sehingga driver Gojek mendapatkan upah dari konsumen. Etika bisnis Islam melihat praktek pembatalan sepihak dari konsumen ini tidak benarkan, karena dalam bisnis Islam tidak boleh saling merugikan dan seharusnya saling menguntungkan. Sikap dari konsumen yang melakukan pembatalan sepihak ini tidak di anjurkan oleh etika bisnis Islam.
\end{abstract}

Kata Kunci : Etika Bisnis Islam, Pembatalan Sepihak, Go Food.

\section{Pendahuluan}

Kemajuan teknologi yang semakin intensif yang dimanfaatkan oleh para bisnis bertujuan untuk mengelola bisnisnya agar bisa meningkatkan kinerja bisnisnya, maka pergeseran teknologi ini membuat para penjual produk ataupun jasanya melalui sebuah handphone dengan adanya sebuah aplikasi. Ecommerce merupakan suatu aplikasi pendorong kemajuan transaksi penjualan, pembelian jasa ataupun barang dilakukan melalui handphone maupun 
komputer. ${ }^{1}$ Dengan itu perusahaan Gojek yang awalnya hanya menggunakan nomor telpon setelah itu berkembang dengan membuat suatu aplikasi yang berbasis online dengan menyuguhkan para konsumen untuk menggunakan menu didalamnya, Gojek ini merupakan sebuah perusahaan yang menyediakan jasa untuk para konsumen dengan cara menggunakan kecanggihan sebuah teknologi yang berupa handphone.

Terdapat tiga pilar Gojek yang menjadi simbol yaitu kecepatan dalam melayani serta akan terus berkembang, inovasi untuk selalu berkarya dalam memperbaiki layanan yang akan memberikan kemudahan bagi para pengguna aplikasi Gojek dan dampak sosial dari Gojek akan konsisten untuk menciptapkan dampak sosial yang positif bagi para pengguna aplikasi Gojek. ${ }^{2}$

Layanan jasa Gojek yang dapat dimanfaatkan oleh konsumen yang sedang membutuhkan yaitu, Go-Ride, Go-Car, Go-Food, Go-Sent, Go-Pulsa, Go-Points, Go-BlueBrid, Go-Nearby, Go-Shop, Go-Mart, Go-Box, GoMassage, Go-Daily, Go-Clean, Go-Fix, Go-Laundry, Go-Glam, Go-Tix, GoAuto, Go-Med, Go-Fitness, Go-News, Go-Games, dan Go-Pay.

Gojek merupakan perusahaan yang menyediakan aplikasi sehingga perusahaan Gojek memiliki hubungan kemitraan antara perusahaan Gojek selaku penyedia dan driver. Hubungan kemitraan ini berhubungan dengan perjanjian bagi hasil, perjanjian kontrak dan lain-lain. Perjanjian ini termuat dalam Pasal 1338 KUHPer menyatakan bahwa "setiap perjanjian yang dibuat secara sah berlaku sebagai undang-undang bagi mereka yang membuatnya. Sesuatu perjanjian tidak dapat ditarik kembali selain dengan sepakat kedua

\footnotetext{
${ }^{1}$ Candra Ahmad dan Dadang Hermawan, E-Business \& E-Commerce, (Yogyakarta : CV Andi Offset, 2013), 7.

${ }^{2}$ Go-jek. "Tentang Go-jek" dalam https://www.gojek.com/about/
} 


\section{Novia Silviani | Implementasi Etika Bisnis...}

belah pihak, atau karena alasan-alasan yang oleh undang-undang dinyatakan cukup untuk itu. Suatu perjanjian harus dilaksanakan dengan itikad baik". 3

Pasal 1320 berisikan "untuk sahnya suatu perjanjian diperlukan empat syarat : Sepakat mereka yang mengikatkan dirinya, Kecakapan untuk membuat suatu perikatan, Suatu hal tertentu dan Suatu sebab yang halal". ${ }^{4}$ Hubungan kemitraan antara driver Gojek dengan konsumen adalah sebagai penyedia layanan jasa yang akan memberikan manfaat kepada konsumen setiap hari. Driver Gojek sudah tersebar di berbagai kota bahkan kabupaten di Indonesia, sehingga semakin banyak pula permasalahan yang dihadapi oleh para driver Gojek dari konsumen.

Permasalahannya adalah pada pemesanan makanan maupun minuman, pemesanan yang dilakukan oleh konsumen yang berujung pada praktek pembatalan sepihak. Konsumen telah memesan makanan atau minuman maka dari itu driver Gojek akan menerima pesanan setelah itu driver Gojek bergegas ke tempat merchant yang dipesan oleh konsumen akan tetapi setelah makanan atau minuman sudah siap diantar pihak konsumen ini dengan tegas ingin membatalkan pesanannya maka kerugian dialami oleh driver Gojek karena konsumen yang keras membatalkan pesanannya.

Pembatalan sepihak ini menimbulkan kerugian dan tidak ada tanggung jawab bahkan inisiatif dari konsumen untuk mengganti biaya kerugian tersebut yang telah mengeluarkan uangnya untuk membayar pesanan dari konsumen. Pembatalan sepihak ini dirasakan oleh driver Gojek yang awalnya akan mendapatkan keuntungan dari orderan konsumen akan tetapi kerugian yang didapatkan.

\footnotetext{
${ }^{3}$ Kitab Undang-Undang Hukum Perdata, (Jakarta : PT. Pradnya Paramita, 2009), 342

${ }^{4}$ Ibid., 339.
} 
Terdapat dalam Al-Qur'an surah Al-Thalaq : 6

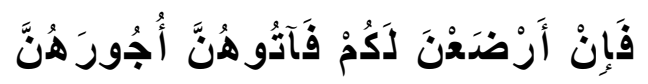

"kemudian jika mereka menyusukan (anak-anak)mu untukmu maka berikanlah kepada mereka upahnya". (Al-Thalaq : 6$)^{5}$

Ayat tersebut menjelaskan bahwa seorang konsumen memberikan upah kepada driver Gojek merupakan sebuah kewajiban karena telah membelikan orderan makanan atau minuman ke konsumen walaupun konsumen melakukan pembatalan sepihak. Seharusnya konsumen wajib membayarkan upah untuk driver Gojek dengan jumlah nominal pesanan atau membayar setengah harga sehingga driver Gojek tidak mengalami kerugian.

\section{Metode}

Penelitian bersifat kualitatif yaitu temuan-temuan yang berada di lapangan atau berupa data-data dengan mendatangi responden. ${ }^{6}$ Temuan yang didapatkan menggunakan cara yuridis empiris sesuai kenyataan yang ada di masyarakat, pengalaman pribadi dan pengamatan langsung. ${ }^{7}$ Peneliti langsung datang ke lapangan untuk memperoleh data secara realita.

Lokasi penelitian di wilayah Kabupaten Jombang. Waktu penelitian berada pada bulan Februari-Maret. Sumber data menggunakan data primer yang diperoleh melaui observasi, wawancara dan interview dari sumbernya. Selain itu peneliti juga menggunakan data sekunder adalah kumpulan dari

${ }^{5}$ Al-qur'an Dan Terjemahnya, Kementrian Agama RI, (Semarang : Asy-Syifa') 2009.

${ }^{6}$ Lexy Meleong, Metode Penelitian Kualitatif. Cet. XXVII (Bandung : Remaja Rosdakarya, 2010), 6.

${ }^{7}$ Mukti Fajar dan Yulianto Achamd, Dualisme Penelitian Hukum Normatif dan Empiris, (Yogyakarta : Pustaka Pelajar, 2010), 81. 


\section{Novia Silviani | Implementasi Etika Bisnis...}

beberapa buku mengenai hukum (Undang-Undang), Al-Qur'an, Al-Hadist maupun bacaan yang lainnya. ${ }^{8}$

Teknik Analisis Data menggunakan wawancara, observasi dan dokumentasi. Sesudah data terkumpul maka akan dianalisis menggunakan metode deskriptif adalah analis yang memberikan gambaran atau fakta atas objek dan subjek berhubungan dengan masalah-masalah yang ada dalam masyarakat dengan fenomena sedang berlangsung. ${ }^{9}$

Setelah itu menggunakan metode deduktif yang mengungkap fakta dari hasil penelitian untuk menarik kesimpulan dengan mengatahui nilai-nilai kebenaran dan keadilan maka teori ini akan mengulik tentang Implementasi Etika Bisnis Islam Terhadap Pembatalan Sepihak Pada Aplikasi Gojek Menu Go Food

\section{Pembahasan}

\section{Praktek Pembatalan Sepihak dan Alasan Konsumen Maupun Driver Gojek Melakukan Pembatalan Sepihak Menu Go Food}

Go Food merupakan menu yang disuguhkan kepada konsumen dari Gojek dengan tujuan memudahkan konsumen untuk membeli makanan atau minuman konsumen inginkan. Alasan konsumen menggunakan menu Go Food yaitu :

a. Gojek sering memberikan diskon dan promo di menu Go Food,

b. Konsumen tidak perlu repot-repot untuk datang ke restoran yang dituju,

c. Pembayaran mudah dan cepat, dan

d. Menu Go Food memberikan penawaran berbagai macam makanan dan minuman yang sudah terdaftar di Gojek.

\footnotetext{
${ }^{8}$ Mukti Fajar dan Yulianto Achmad, Dualisme Penelitian Hukum Normatif dan Empiris, (Yogyakarta : Pustaka Pelajar, 2010), 157.

9 Mukti Fajar dan Yulianto Achmad, Dualisme Penelitian Hukum Normatif \& Empiris. (Yogyakarta : Pustaka Pelajar, 2010), 183.
} 
Alasan konsumen menggunakan menu Go Food tidak diimbangi dengan sikap baik untuk tidak melakukan pembatalan sepihak, tetapi fakta yang ada di lapangan konsumen tetap melakukan praktek pembatalan sepihak ini. Alasan konsumen melakukan pembatalan sebagai berikut :

a. Konsumen salah memesan jumlah makanan yang sudah di order,

b. Restoran tidak melayani pemesanan di Go Food dan restoran sudah tutup,

c. Orderan fiktif, alamat yang diberikan oleh konsumen palsu serta nama pengguna aplikasi Gojek dipalsukan atau disamarkan, dan

d. Pesanan yang dikirim tidak sesuai yang dipesan atau salah memesankan makanan.

Faktor yang mempengaruhi pembatalan sepihak yang dilakukan oleh konsumen maupun driver Gojek adalah :

a. Faktor tentang orderan fiktif yang merupakan orderan palsu yang dilakukan oleh konsumen dengan memiliki niatan untuk menipu driver Gojek. Ciri-ciri orderan fiktif adalah :

1. Akun yang berisikan data pribadi di aplikasi Gojek palsu dengan kata lain data tidak sesuai dengan pengguna aplikasi Gojek,

2. Alamat yang ditulis merupakan alamat palsu. Titik tempat penerimaan orderan Go Food tidak jelas pada saat driver Gojek mengantarkan orderan.

3. Nomor handphone awal aktif setelah driver Gojek mengantarkan orderan tiba-tiba nomor tersebut tidak aktif lagi.

b. Faktor tentang aplikasi Gojek mengalami error. Aplikasi Gojek yang mengalami error yang membuat orderan dari konsumen mendadak terbatalkan sendiri dari pihak driver Gojek, maka error ini yang membatalkan adalah driver Gojek dengan alasan aplikasi yang tiba-tiba 


\section{Novia Silviani | Implementasi Etika Bisnis...}

error. Aplikasi error juga disebabkan karena Handphone yang dimiliki oleh driver Gojek tidak layak pakai dengan kapasitas RAM 2 yang sering mengalami ke error-an, tetapi yang sering dirasakan adalah aplikasinya mengalami ke error-an. Dan,

c. Faktor terakhir tentang orderan asli. Faktor yang terakhir merupakan konsumen tidak memiliki niatan yang buruk kepada driver Gojek, tetapi konsumen melaksanakan pembatalan ini disebabkan kesalahannya konsumen sendiri dengan melakukan pembatalan secara sepihak.

Akibat dari pembatalan sepihak yang membawa dampak bagi driver Gojek, yaitu :

a. Tenaga

Tenaga yang sudah dikerahkan driver Gojek untuk menuju restoran dipesan oleh konsumen dengan kegigihan tanpa menghiraukan cuaca dalam keadaan hujan maupun terik matahari begitu panas. Secara tiba-tiba konsumen melakukan pembatalan sepihak orderan tersebut, akhirnya driver Gojek telah terbuang tenaga dengan tidak mendapatkan upah yang seharusnya didapatkan.

b. Waktu

Pembatalan sepihak yang dilakukan oleh konsumen kepada driver Gojek menimbulkan kerugian akan tetapi kerugian digantikan pihak perusahaan Gojek, tapi sangat memerlukan waktu yang begitu lama dimana driver Gojek harus kepihak perusahaan bahwa telah mengalami pembatalan dan meminta ganti rugi. Ganti rugi dari perusahaan Gojek tidak langsung mencairkan melainkan harus menunggu seminggu bahkan lebih.

c. Materi 


\section{Novia Silviani | Implementasi Etika Bisnis...}

Kerugian dari sisi uang begitu besar atas pembatalan sepihak yang dilakukan oleh konsumen, kerugian akan terus terulang-ulang karena konsumen memesan makanan dengan harga dari terkecil hingga terbesar yang dimana uang dari konsumen untuk mengisi saldo maupun pulsa untuk menghubungi konsumen dan driver Gojek rugi dari sisi bahan bakar kendaraan yang telah menuju restoran yang diinginkan oleh konsumen.

Pembatalan bukan hanya dilakukan oleh konsumen akan tetapi driver Gojek juga melakukan pembatalan dengan alasan :

a. Sistem aplikasi Gojek yang sedang mengalami error sehingga tiba-tiba pesanan tercancel,

b. Jarak konsumen terlampau jauh,

c. Cuaca tidak mendukung untuk mengambil pesanan,

d. Kendaraan driver Gojek mendadak mogok sehingga harus dibawa kebengkel dan driver Gojek akan membatalkan pesanannya, dan

e. Uang atau saldo yang dimiliki oleh driver Gojek tidak mencukupi untuk mengambil pesanan dari konsumen.

\section{Analisis Etika Bisnis Islam Terhadap Praktek Pembatalan Sepihak} Menu Go Food Aplikasi Gojek

Gojek merupakan perusahaan penyedia jasa berbasis aplikasi yang bisa digunakan oleh konsumen disetiap harinya serta Go Food merupakan menu yang diciptakan perusahaan Gojek dengan menawarkan restoran untuk bergabung juga menjualkan barang yang dijual dengan cara online dan harga ditetapkan oleh restoran. Konsumen merupakan Setiap orang pemakai barang atau jasa yang tersedia dalam masyarakat, baik bagi 


\section{Novia Silviani | Implementasi Etika Bisnis...}

kepentingan diri sendiri, keluarga, orang lain maupun makhluk hidup lain dan tidak untuk diperdagangkan. ${ }^{10}$

Konsumen dapat mengunduh aplikasi Gojek di handphone serta dapat menggunakan dengan bebas, tetapi kekebasan dari konsumen ini ada batas dari ruang gerak, norma-norma serta peraturan-peraturan yang harus dipahami $^{11}$ oleh konsumen. Tetapi kebebasan yang diberikan tidak digunakan dengan baik oleh konsumen maka dari itu konsumen dengan seenaknya melakukan pembatalan sepihak. Pembatalan sepihak dari konsumen merupakan tindakan ingkar janji yang dimana konsumen tidak memenuhi prestasinya sama sekali karena kelalaiannya ${ }^{12}$ sehingga driver Gojek mengalami kerugian.

Pembatalan sepihak yang dilakukan oleh konsumen dalam etika bisnis Islam merupakan tindakan tidak memiliki iktikad baik dalan memesan, yang seharusnya pada etika bisnis Islam harus saling menguntungkan bukan merugikan salah satu pihak. Etika bisnis Islam memandang pembatalan sepihak dari sisi prinsip-prinsip etika bisnis Islam diantaranya :

1. Prinsip Keseimbangan (equilibrium)

Prinsip ini merupakan untuk mengutamakan kesimbangan antara keadilan dalam bisnis maupun transaksi agar tidak timbul kerugian. ${ }^{13}$ Keseimbangan ini tidak digunakan oleh konsumen saat melakukan pemesanan melalui Go Food karena konsumen memperlakukan sebuah

${ }^{10}$ Undang-Undang Perlindungan Konsumen (UU RI NO. 8 TAHUN 1999), (Jakarta Timur : Sinar grafika Offset, 2018), 3. 2016), 12.

${ }^{11}$ Faisal Badroen, DKK, Etika Bisnis dalam Islam, (Jakarta : PranadaMedia Group,

${ }^{12}$ Yahman, Karakteristik Wanprestasi dan Tindak Pidana Penipuan Yang Lahir dari Hubungan Kontraktual, (Jakarta, PrenadaMedia Group, 2014), 82. 2006), 37

${ }^{13}$ Faisal Badroen, DKK, Etika Bisnis dalam Islam, (Jakarta : PrenadaMedia Group, 
tindakan yang tidak adil ke driver Gojek, prinsip keseimbangan merupakan prinsip yang mendasar dimana konsumen harus berbuat adil kepada driver Gojek dengan tidak melakukan pembatalan sepihak dan menyalahkan driver Gojek saat konsumen melakukan pembatalan sepihak sendiri.

2. Prinsip Tanggung Jawab (responsibility) ${ }^{14}$

Tanggung jawab merupakan kepahaman diri manusia kepada tingkah lakunya yang diperbuat karena sengaja maupun tidak sengaja, prinsip tanggung jawab ini harus diterapkan oleh setiap konsumen pada saat melakukan pembatalan sepihak. Alasan dari konsumen yang mengakibatkan kerugian oleh driver Gojek maka konsumen harus bertanggung jawab dengan membayar pesanannya dengan membayar penuh atau setengah dari harga dipesan agar driver Gojek tidak mengalami kerugian yang cukup besar.

\section{Kesimpulan}

Faktor yang mempengaruhi sebuah pembatalan sepihak dikarenakan adanya pesanan fiktif yang dilakukan oleh konsumen, aplikasi Gojek sedang mengalami gangguan atau sedang error dan pesanan asli yang dimana konsumen akan melakukan pembatalan sepihak dengan memesan setelah itu membatalkan dengan berbagai alasan disampaikannya.

Praktek pembatalan sepihak yang dilakukan oleh konsumen pada aplikasi Gojek menu Go Food disertai oleh berbagai macam alasan yang dapat mengakibatkan kerugian pada satu pihak yaitu driver Gojek. Kerugian berupa tenaga, waktu dan materi yang dilakukan oleh konsumen jika pembatalan

${ }^{14}$ Muhamma, Etika Bisnis Islam, (Yogyakarta : Akademi Manajemen Perusahaan YKPN, 2004), 54. 


\section{Novia Silviani | Implementasi Etika Bisnis...}

sepihak yang dilakukan oleh driver Gojek disebabkan karena adanya gangguan aplikasi yang sedang error.

Ditinjau dari implementasi etika bisnis Islam dengan melihat praktek pembatalan sepihak yang dilakukan oleh konsumen merupakan tindakan yang tidak memiliki iktikad baik kepada driver Gojek dimana dalam etika bisnis Islam pembatalan sepihak ini diperbolehkan karena harus ada hubungan saling menguntungkan bukan merugikan pada salah satu pihak, iktikad yang tidak baik dilakukan oleh konsumen sehingga menimbulkan kerugian maka harus tindak lanjutin dengan cara mempertanggung jawabkan perilakunya yang harus membayar setengah harga dari pemesannya.

\section{Daftar Pustaka}

Al-qur'an Dan Terjemahnya, Kementrian Agama RI, (Semarang : Asy-Syifa') 2009.

Ahmad Candra dan Hermawan Dadang, E-Business \& E-Commerce, Yogyakarta : CV Andi Offset, 2013.

Meleong Lexy, Metode Penelitian Kualitatif. Cet. XXVII, Bandung : Remaja Rosdakarya, 2010.

Mahmud Piter Marzuki, Penelitian Kuantitatid, Kualitatif dan R\&D, Jakarta : PranadaMedia Group, 2015.

Fajar Mukti dan Ahmad Yulianto, Dualisme Penelitian Hukum Normatif dan Empiris, Yogyakarta : Pustaka Pelajar, 2010.

Badroen Faisal, DKK, Etika Bisnis dalam Islam, Jakarta : PrenadaMedia Group, 2006.

Muhammad, Etika Bisnis Islami, Yogyakarta : Akademi Manajemen Perusahaan YKPN, 2004.

Yahman, Karakteristik Wanprestasi dan Tindak Pidana Penipuan Yang Lahir dari Hubungan Kontraktual, Jakarta : PrenadaMedia Group, 2014. 
Novia Silviani | Implementasi Etika Bisnis...

Kitab Undang-Undang Hukum Perdata, Jakarta : Penerbit Bhuana Ilmu Populer, 2018.

Undang-Undang Perlindungan Konsumen (UU RI NO. 8 TAHUN 1999), Jakarta Timur : Sinar Grafika, 2018.

Go-jek. "Tentang Go-jek" dalam https://www.gojek.com/about/ 